\title{
Cardiovascular magnetic resonance TE-averaged susceptibility weighted imaging of reperfused intramyocardial hemorrhage
}

\author{
James W Goldfarb*, Usama Hasan \\ From 18th Annual SCMR Scientific Sessions \\ Nice, France. 4-7 February 2015
}

\section{Background}

In the setting of acute myocardial infarction (AMI), therapeutic and spontaneous reperfusion of ischemic myocardium can lead to interstitial intramyocardial hemorrhage (IMH) which is associated with microvascular obstruction (MVO) and subsequent adverse clinical outcomes. Imaging without contrast agents (native imaging) can be used in AMI patients for additional myocardial tissue characterization. Native T1 and T2 weighted imaging and quantitative measurements have been reported to detect myocardial edema and depict the myocardial area at risk. IMH affects T1, T2 and T2* relaxation as well as susceptibility and the feasibility of several MR image contrasts (T1, T2, T2* and gradientecho phase) has been demonstrated for the depiction of IMH. Susceptibility weighted imaging (SWI) uses a type of image contrast different from traditional spin density, T1 or T2 weighted MR imaging.

In the present work, we report our experience with myocardial SWI imaging (combined gradient-echo magnitude and phase imaging) for the detection of IMH. We propose TE image averaging and gray-scale inversion as a means of providing a single image with good image SNR and excellent contrast for the detection of $\mathrm{IMH}$.

\section{Methods}

Eleven AMI subjects were studied at $1.5 \mathrm{~T}$ before contrast agent administration with a dark blood double inversion recovery multiple spoiled gradient-echo sequence (12 echo times, $2.4-15.5 \mathrm{~ms} ; 1.2 \mathrm{~ms}$ spacing) and conventional CINE and late gadolinium-enhanced (LGE) imaging. Magnitude, susceptibility weighted and

St Francis Hospital, Roslyn, NY, USA (http://creativecommons.org/publicdomain/zero/1.0/) applies to the data made available in this article, unless otherwise stated.
TE-averaged images were reconstructed from raw data k-space data. Contrast and signal-difference-to-noise were measured and compared between SWI methods for IMH detection. Volumes of LGE, IMH and MVO were measured and reported as a percentage of LV myocardial volume.

\section{Results}

There were six patients with microvascular obstruction (MVO) and four patients with IMH detected by TEaveraged SWI imaging. TE-averaged SWI images from a representative AMI subject with IMH are given in Figure 1. All patients with IMH on SWI scans had MVO on late gadolinium-enhanced (LGE) imaging. There was a three-fold increase in IMH contrast with SWI compared to magnitude images. IMH contrast decreased and signal-to-noise increased with increased TE averages. Results of IMH, LGE and MVO volume measurements are displayed in Figure 2. The trend was that larger infarcts had MVO and IMH, but this was not true in all cases as the largest infarct had no evidence of IMH.

\section{Conclusions}

TE-averaged SWI imaging is a promising method for myocardial tissue characterization in the setting of AMI for the detection of IMH. Along with gray-scale colormap inversion, it combines not only magnitude and phase information, but also images across TEs to provide a single image sensitive to IMH with characteristics similar to LGE imaging.

\section{Funding}

American Heart Association scientist development grant $(0635029 \mathrm{~N})$. 

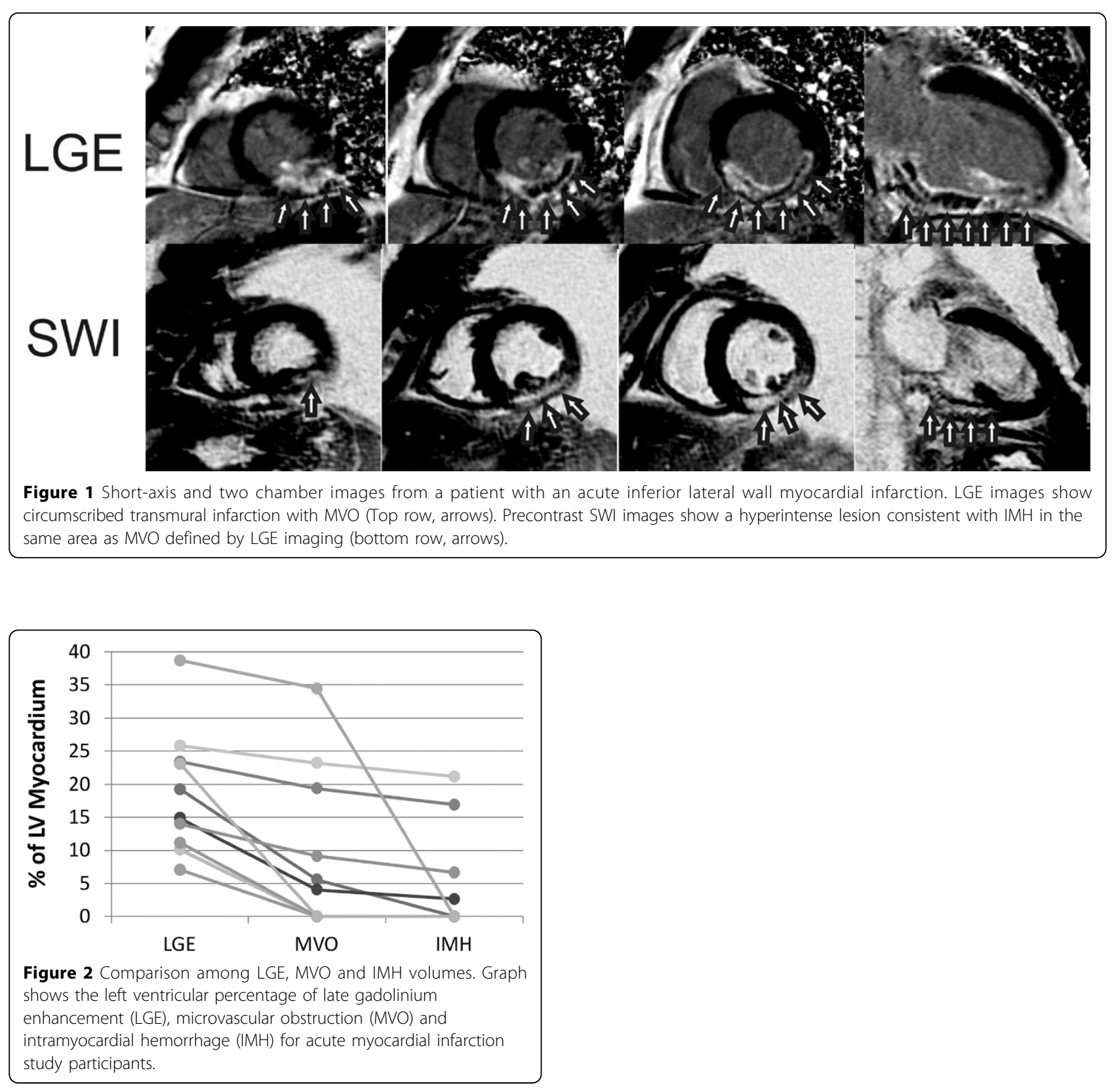

Submit your next manuscript to BioMed Central and take full advantage of:

- Convenient online submission

- Thorough peer review

- No space constraints or color figure charges

- Immediate publication on acceptance

- Inclusion in PubMed, CAS, Scopus and Google Scholar

- Research which is freely available for redistribution 